\title{
Effect of Electromagnetic Boundary Conditions on Reliability of Plasma Torch Models
}

\author{
Rodion Zhukovskii ${ }^{1} \cdot$ Christophe Chazelas $^{1} \cdot$ Armelle Vardelle $^{1} \cdot$ Vincent Rat $^{1}$ \\ Bernd Distler ${ }^{2}$
}

Submitted: 21 August 2019/in revised form: 24 April 2020/Published online: 27 May 2020

(C) The Author(s) 2020

\begin{abstract}
The cascaded-anode plasma torch makes it possible to get a longer and more stable plasma jet with higher specific enthalpy than conventional plasma torches. It is now used widely, but there are still few models of the cascaded-anode plasma torch. This study developed a 3-D time-dependent model that couples the gas phase and electrodes by encompassing the electromagnetic and heat equations both in the electrodes and gas phase. The model was applied to a commercial plasma spray gun equipped with a single cathode, single cylindrical anode and an interelectrode insert to fix the average arc length. This paper examines the effect of the boundary conditions for the magnetic vector potential and electric current density on the electromagnetic, velocity and temperature fields of the plasma jet. The model predictions showed that, for such plasma torches where the arc is close to walls, the Biot and Savart formalism is required at the domain boundaries for the magnetic vector potential. They also showed that similar plasma fields could be obtained by imposing an electric current density profile at the cathode tip or by including the electrodes in the computational domain. However, this profile has to be chosen according to the specific design of the cathode, which is not obvious when the cathode has a design different from that of conventional plasma torches with sharp conical tip or rounded tip.
\end{abstract}

Keywords atmospheric plasma spray (APS) . computational fluid dynamics - electric arc model - heat transfer $\cdot$ modeling $\cdot$ torch modeling

Rodion Zhukovskii

rodion.zhukovskii@unilim.fr

1 University of Limoges, Limoges, France

2 Oerlikon Metco (US) Inc, Westbury, NY, USA

\section{List of Symbols}

$\vec{A} \quad$ Magnetic vector potential $\left(\mathrm{V} \mathrm{s} \mathrm{m}^{-1}\right)$

$\vec{B} \quad$ Magnetic field (T)

$C_{p} \quad$ Specific heat $\left(\mathrm{J} \mathrm{kg}^{-1} \mathrm{~K}^{-1}\right)$

$\vec{E} \quad$ Electric field $\left(\mathrm{V} \mathrm{m}^{-1}\right)$

$f_{\psi} \quad$ Net flux of $\psi$

$e \quad$ Electron charge $(c)$

$h \quad$ Enthalpy $\left(\mathrm{J} \mathrm{kg}^{-1}\right)$

I Arc current (A)

$\vec{J} \quad$ Electric current density $\left(\mathrm{A} \mathrm{m}^{-2}\right)$

$J_{0} \quad$ Electric current density at the cathode tip center $\left(\mathrm{A} \mathrm{m}^{-2}\right.$ )

$J_{\text {elec }} \quad$ Electric current density due to electrons $\left(\mathrm{A} \mathrm{m}^{-2}\right)$

$J_{\text {ions }} \quad$ Electric current density due to ions $\left(\mathrm{A} \mathrm{m}^{-2}\right)$

$k_{\mathrm{b}} \quad$ Boltzmann constant $\left(\mathrm{J} \mathrm{K}^{-1}\right)$

$Q_{\mathrm{J}} \quad$ Joule heating $\left(\mathrm{J} \mathrm{kg}^{-1}\right)$

$Q_{\mathrm{r}} \quad$ Radiation loss $\left(\mathrm{J} \mathrm{kg}^{-1}\right)$

$Q \quad$ Total heat loss to electrodes (J)

$R_{\text {arc }} \quad$ Cathode arc attachment radius (m)

$t \quad$ Time (s)

$T \quad$ Temperature (K)

$\vec{u} \quad$ Fluid velocity $\left(\mathrm{m} \mathrm{s}^{-1}\right)$

$U \quad$ Arc voltage (V)

$U_{\mathrm{a}} \quad$ Anode voltage drop (V)

$U_{\mathrm{c}} \quad$ Cathode voltage drop (V)

$\Delta W \quad$ Schottky reduction of the work function $(\mathrm{eV})$

$\lambda$ Thermal conductivity ( $\mathrm{W} \mathrm{m}^{-1} \mathrm{~K}^{-1}$ )

$\rho \quad$ Fluid density $\left(\mathrm{kg} \mathrm{m}^{-3}\right)$

$\overline{\bar{\tau}} \quad$ Shear stress tensor $(\mathrm{Pa})$

$\varphi \quad$ Electric potential (V)

$\Phi_{\mathrm{W}} \quad$ Tungsten work function (eV)

$\Phi_{i} \quad$ Argon ionization energy $(\mathrm{eV})$

$S_{\psi} \quad$ Net production or depletion rate

$\psi \quad$ Conserved property 
$\mu_{0} \quad$ Vacuum permeability $\left(\mathrm{H} \mathrm{m}^{-1}\right)$

\section{Introduction}

Simulation of the plasma jet generation in DC plasma torches is a necessary tool for system design and operation improvement if it can mimic accurately the generation and behavior of the arc and predict the heat fluxes to the electrodes and the plasma flow at the nozzle exit. However, the level of predictability of the current models can be limited by the assumptions and boundary conditions. Recent reviews (Ref 1-3) pointed out two issues that often receive limited attention in the modeling of plasma spray torches:

a. the way the direct electric current is transferred to the cathode,

b. the boundary conditions imposed on the magnetic vector potential.

In most cases, the computational domain is limited to the gas phase and the current density profile is imposed at the cathode tip: It is generally assumed to be of a parabolic or an exponential form as follows (e.g., Ref 4-6):

$J(r)=J_{0} \cdot\left(1-\left(\frac{r}{R_{\text {arc }}}\right)^{n}\right)$

$J(r)=J_{0} \cdot \exp \left(-\left(\frac{r}{R_{\operatorname{arc}}}\right)^{n}\right)$

Both equations involve constants that are chosen by the user and which may affect the model predictions. In addition, this assumption omits a part of the actual geometry of the torch: the gas chamber upstream of the cathode tip, although it has been experimentally shown that the geometry and volume of this chamber affects the behavior of the arc $(\operatorname{Ref} 7,8)$. Another possibility is to include the electrodes in the computational domain, impose the current on the rear of the cathode and solve the heat and electromagnetic equations both in the electrodes and gas phase. With the more powerful hardware platforms and improved simulation techniques now available, this should be the proper approach as has been done for numerical simulations of welding technology (Ref 9-11) and more recently for thermal spraying ( $\operatorname{Ref} 12,13)$. The problem is then to model the arc-electrode interfaces.

In DC spray plasma torches with self-setting arc length or fixed average arc length, the arc attachment on the anode wall moves and can exhibit one or several roots. In any case, the electric arc between anode and cathode presents some dissymmetry. Therefore, recent models of plasma torch use a 3-D geometry and the magnetic vector potential approach to predict the magnetic field generated by the circulation of the arc current. However, the boundary conditions imposed on the magnetic vector potential can affect the accuracy of the model predictions and this point is rarely discussed. The most often used boundary condition is a null flux imposed on the components of the magnetic vector potential at the physical limits of the domains or a zero value when these limits are far from the arc. Freton et al. (Ref 14) showed that this approach can result in wrong predicted self-magnetic and, thus, velocity fields for free burning or constricted transferred arcs. They proposed calculation of the exact values of the vector potential at the domain boundaries by using the Biot and Savart (B\&S) law. They also showed that with this method the predictions of magnetic and velocity fields were similar to those obtained with the B\&S formulation used in the whole domain but at a shorter time of calculation.

This study used a 3-D time-dependent model of the arc that includes the electrodes in the computational domain. First, we examined the effect of the boundary conditions used for the magnetic vector potential on the predicted electromagnetic and hydrodynamics fields. Then, on the basis of the correct boundary conditions, we calculated these fields for different torch operating conditions and compared the predicted arc voltage and heat losses to electrodes with experimental data. Finally, we tried to answer the question: Is it possible to get the same results with a model that considers only the gas phase and, thus, uses a current density profile imposed at the cathode tip as boundary condition?

The model was applied to a commercial plasma torch, the Oerlikon Metco SinplexPro ${ }^{\mathrm{TM}}$ Plasma Spray Gun. This plasma torch has a single cathode and a cascaded anode. The latter consists of a stack of copper rings insulated from each other and ending with an anode ring. The insulated inter-electrode insert forces the arc to attach to this last ring and, so, limits the pulsation of arc voltage. The point of using this torch for calculations is that the arc attachment process at the anode wall is limited to an oscillating movement along a line that can be predicted easily. This allowed us to focus our attention to the cathode-arc interface where the arc originates.

\section{Model Description}

\section{Physical Model}

The geometry of the actual plasma torch is shown in Fig. 1 and computational domain in Fig. 2. The latter involved the arc chamber from the rear of the cathode to the nozzle exit (51 mm long) and an outside domain (36 mm long). The cathode and anode were included in the computational domain. The cathode was assumed to be made of pure 


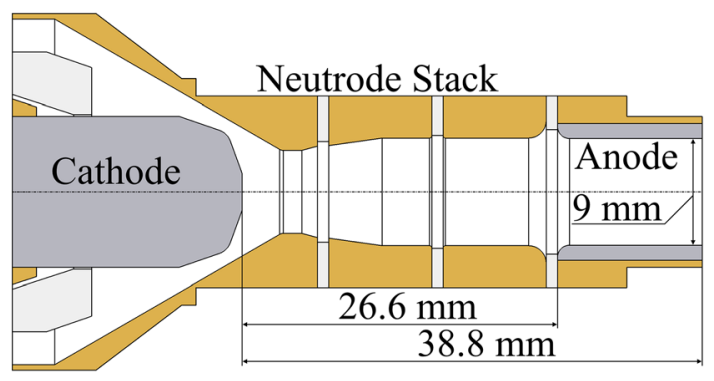

Fig. 1 Plasma torch schematic

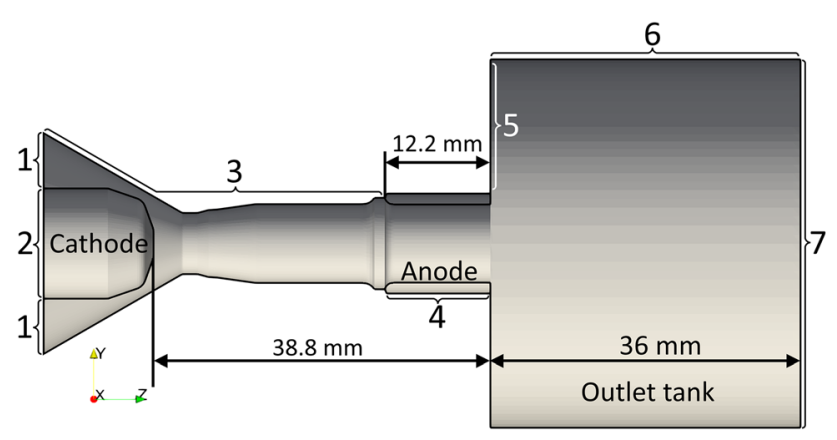

Fig. 2 Computational domain: 1: inlet of plasma-forming gas; 2: rear of the cathode; 3: electrically insulating inter-electrode; 4: anode; 5 and 6: cold wall; 7: outlet

tungsten, and the anode was lined with pure tungsten. This tungsten liner protects the copper anode from erosion and copper spitting. The anode-nozzle exit diameter was $9 \mathrm{~mm}$.

In this study, the plasma torch was operated with argon as plasma-forming gas. The operating conditions were selected from the operating window recommended by the manufacturer (Ref 15). The arc current was varied between 100 and $500 \mathrm{~A}$ and the gas flow rate between 60 and 120 NLPM. ${ }^{1}$

\section{Mathematical Model}

The model solved the unsteady Navier-Stokes equations for a non-isothermal fluid coupled with the Maxwell equations of electromagnetic fields in both the gas and solid phases (electrodes).

The gas flow inside and outside the torch was supposed to be weakly compressible and laminar (Ref 12$)$. Actually, a recent review of turbulence modeling in thermal plasma flows (Ref 16) concluded that (1) the turbulence transition is dominated by fluid dynamic instabilities once the plasma jet issues from the plasma torch rather than non-uniform or unsteady phenomena in the plasma torch, and (2) the

\footnotetext{
${ }^{1}$ NLPM units of flow Rate, practiced in Europe, define what shall be a flow Rate of a given gas stream at $T_{\text {gas }}, P_{\text {gas }}$ temperature and pressure, if it changed to pressure of $1 \mathrm{~atm}(101.325 \mathrm{kPa})$ and temperature of $20^{\circ} \mathrm{C}(293.15 \mathrm{~K})$.
}

development of turbulence in the outside plasma flow does not affect the flow inside the plasma torch (Ref 16). In addition, the plasma was optically thin and local thermodynamic equilibrium (LTE) prevailed in the whole gas phase of the computational domain. The electromagnetism phenomena were assumed to be quasi-steady, which is admitted to be pertinent in arc plasmas (Ref 17, 18).

The fluid model equations were expressed as a balance of accumulation, net flux by convection and diffusion and net production according to the following equation:

$\frac{\partial \psi}{\partial t}+\vec{\nabla} \cdot f_{\psi}=S_{\psi}$

where $\psi$ is a conserved property, $t$ the time, $f_{\psi}$ the net flux of $\psi$, and $S_{\psi}$ the net production or depletion rate.

The set of conservation and electromagnetism equations describing the LTE plasma are shown in Table 1.

In Table $1, \vec{u}$ and $h$ are the fluid velocity and enthalpy; $\vec{J}, \vec{B}$ and $\vec{E}$ are the electric current density, magnetic field and electric field, respectively; $\varphi$ and $\vec{A}$ are the electric and magnetic potential, $\rho, \lambda, C_{p}$ are the fluid density, thermal conductivity and specific heat, respectively, $\mu_{0}$ is the permeability constant $\left(4 \pi \times 10^{-7} \mathrm{H} \mathrm{m}^{-1}\right)$.

In the momentum conservation equation, $\overline{\bar{\tau}}$ is the shear stress tensor, $\vec{J} \wedge \vec{B}$ represents the electromagnetic Lorentz force, and $\Gamma_{\text {impl }}$ is a source term that brings the velocity to zero in the solid phase $\left(-\Gamma_{\text {impl }}=-10^{30}\right)(\operatorname{Ref} 19)$. In the energy equation, the term $Q_{\mathrm{J}}$ represents the Joule heating and $Q_{\mathrm{r}}\left(\mathrm{W} \mathrm{m}^{-3}\right)$ the radiation loss. It corresponds to a net emission coefficient defined as a function of the local temperature, which has been taken from Ref 20 .

The predicted electric potential $\varphi$ was used to deduce the electric field, current density and Joule heating as follows:

$\vec{E}=-\vec{\nabla} \varphi$

$\vec{J}=\sigma \vec{E}$

$Q_{\mathrm{J}}=\vec{E} \cdot \vec{J}$

The magnetic field $\vec{B}$ was calculated from the magnetic vector potential $\vec{A}$ as:

$\vec{B}=\vec{\nabla} \wedge \vec{A}$

The LTE transport coefficients and thermodynamic properties of the argon plasma were taken from Murphy (Ref 21).

\section{Boundary Conditions}

The set of fluid and electromagnetic equation were solved using the boundary conditions shown in Table 2 . 
Table 1 Fluid and electromagnetic equations

Table 2 Boundary conditions

\begin{tabular}{lccc}
\hline Quantity $\psi$ & Transient term & Advection and diffusion of $\psi$ & Source terms $S_{\psi}$ \\
\hline Mass $\rho$ & $\partial_{t} \rho$ & $\operatorname{div}(\rho \vec{u})$ & 0 \\
Momentum $\vec{u}$ & $\partial_{t} \rho \vec{u}$ & $\operatorname{div}(\rho \vec{u} \otimes \vec{u}-\overline{\bar{\tau}}+p \overline{\overline{1}})$ & $\vec{J} \wedge \vec{B}-\Gamma_{\text {impl } \vec{u}}$ \\
Thermal energy $h$ & $\partial_{t} \rho h$ & $\operatorname{div}\left(\rho \vec{u} h-\frac{\lambda}{C_{p}} \vec{\nabla} h\right)$ & $Q_{\mathrm{J}}-Q_{\mathrm{r}}$ \\
Electric potential $\varphi$ & 0 & $\operatorname{div}(\sigma \vec{\nabla}(\varphi))$ & 0 \\
Magnetic vector potential $\vec{A}$ & 0 & $\operatorname{div}(\vec{\nabla}(\vec{A}))$ & $-\mu_{0} \vec{J}$ \\
\hline
\end{tabular}

\begin{tabular}{lllll}
\hline Boundary & \multicolumn{1}{c}{$\vec{u}$} & \multicolumn{1}{c}{$T$} & \multicolumn{1}{c}{$\varphi$} & \multicolumn{1}{c}{$A$} \\
\hline 1: Inlet & $\vec{u}=\vec{u}_{\text {inlet }}$ & $T=300 \mathrm{~K}$ & $\partial_{n} \varphi=0$ & $\begin{array}{l}\text { PVNF condition: } \partial_{n} A_{i}=0 \\
\text { B\&S condition: Eq } 8\end{array}$ \\
2: Cathode & $\vec{u}=0$ & $T=300 \mathrm{~K}$ & $\varphi=U(t)(\mathrm{a})$ & $\begin{array}{l}\text { PVNF: } \partial_{n} A_{i}=0 \\
\text { B\&S: Eq } 8\end{array}$ \\
3: Internal torch boundary & $\vec{u}=0$ & $T=300 \mathrm{~K}$ & $\partial_{n} \varphi=0$ & $\begin{array}{l}\text { PVNF: } \partial_{n} A_{i}=0 \\
\text { B\&S: Eq } 8\end{array}$ \\
& & & & $\begin{array}{l}\text { PVNF: } \partial_{n} A_{i}=0 \\
\text { 4: Anode }\end{array}$ \\
& $\vec{u}=0$ & $T=400 \mathrm{~K}$ & $\varphi=0$ & $\begin{array}{l}\text { B\&S: Eq } 8 \\
\text { PVNF: } \partial_{n} A_{i}=0\end{array}$ \\
5: Outside plain wall & $\vec{u}=0$ & $T=300 \mathrm{~K}$ & $\partial_{n} \varphi=0$ & B\&S: Eq 8 \\
& & & & PVNF: $A_{i}=0$ \\
6: Outside cylindrical wall & $\vec{u}=0$ & $T=300 \mathrm{~K}$ & $\partial_{n} \varphi=0$ & B\&S: Eq 8 \\
& & & & PVNF: $A_{i}=0$ \\
7: Outlet & $\partial_{n} u_{i}=0$ & $\partial_{n} T=0$ & $\partial_{n} \varphi=0$ & B\&S: Eq 8
\end{tabular}

(a) The voltage imposed on the rear of the cathode was corrected at each time step with respect to the total Joule power in order to maintain the imposed electric current through the computational domain. This allowed to dynamically predict the arc voltage
For the magnetic vector potential $\vec{A}$, two types of boundary conditions were used:

1. Null flux at boundaries inside the plasma torch and null value at the outlet boundary and outside cylindrical wall. We will refer it as PVNF according to the notation used in the paper of Freton et al. (Ref 14).

2. Calculated boundary conditions with the Biot\&Savart formulation after Eq 8. We will refer it as B\&S (Ref 14).

$$
\vec{A}(\vec{r})=\frac{\mu_{0}}{4 \pi} \iiint_{\text {domain }} \frac{\vec{J}\left(\overrightarrow{r^{\prime}}\right)}{\left|\vec{r}-\overrightarrow{r^{\prime}}\right|} \mathrm{d} V
$$

\section{Thermal and Electric Coupling at the Fluid- Electrode Interfaces}

The electric current density at the cathode surface consists in an ion $\left(J_{\text {ions }}\right)$ contribution and an electron $\left(J_{\text {elec }}\right)$ contribution. The latter includes the charge flux of electrons due to the thermionic emission and secondary emission at the cathode surface and charge flux of electrons back-diffused from the plasma. The electron secondary emission results from the collision of an ion that brings to the cathode surface an energy larger than the work function. In the conditions of this study, the electron secondary emission and back-diffusion flux were supposed to be negligible compared to the thermionic flux (Ref 22). Actually, the works of Cayla et al. (Ref 23) and Neumann (Ref 24) showed that the secondary electron emission is significant for current density below $10^{6} \mathrm{~A} \mathrm{~m}^{-2}$ and important rather under glow discharge conditions than arc conditions. Furthermore, Benilov et al. (Ref 25) calculated that when the tungsten cathode tip is around the melting point $\left(T_{\text {cathode }} \approx 3700 \mathrm{~K}\right.$ ) and the plasma temperature $T_{\text {plasma }}$ is about $15,000 \mathrm{~K}$, the electrons back-diffused from the plasma contribute only about $10 \%$ to the total electric current density. 
The thermionic flux was calculated from the Richardson-Dushman emission law supplemented with Schottky correction (Ref 26):

$J_{\mathrm{em}}=A_{G} T_{\text {cathode }}^{2} \exp \left(-\frac{\Phi_{\mathrm{W}}-\Delta W}{k T_{\text {cathode }}}\right)$

where $A_{G}=6 \times 10^{5} \mathrm{~A} \mathrm{~m}^{-2} \mathrm{~K}^{-2}$ and Tungsten work function $\Phi_{\mathrm{W}}=4.5 \mathrm{eV}$. Both values were taken from Reimann (Ref 27). The Schottky reduction of the work function $\Delta W$ was supposed to be equal to $0.2 \mathrm{eV}$ for $500 \mathrm{~A}$, $0.1 \mathrm{eV}$ for $200 \mathrm{~A}$ and $0 \mathrm{eV}$ for $100 \mathrm{~A}$ (Ref 25).

The Richardson-Dushman law applies for thermionic emission enhanced by the cathode surface electric field. It is commonly used for hot cathodes at high surface temperature and low surface electric field $\left(<10^{8} \mathrm{~V} \mathrm{~m}^{-1}\right)$ (Ref 26).

The ion current density was calculated as the balance between the calculated electric current density and electron emission contribution:

$J_{\text {ions }}=J_{\text {calculated }}-J_{\text {emis }}$

The heat flux to electrodes was dissipated by conduction in the bulk of electrodes. At the cathode surface, the heat flux due to the charge flux was written as follows (Ref $23,26):$

$$
\begin{aligned}
Q_{\text {cathode }}= & -J_{\text {emis }} \cdot\left(\frac{2 k_{\mathrm{b}}}{e} T_{\text {cathode }}+\frac{\Phi_{\mathrm{W}}}{e}\right) \\
& +J_{\text {ions }} \cdot\left(\frac{5 k_{\mathrm{b}}}{2 e} T_{\text {plasma }}+U_{\mathrm{c}}+\frac{\Phi_{\mathrm{i}}}{e}\right)
\end{aligned}
$$

and at the anode surface, assuming that the heat flux linked to the ion flux was negligible (Ref 23,26 ):

$Q_{\text {anode }}=J_{\text {elec }}\left(\frac{5 k_{\mathrm{b}}}{2 e} T_{\text {electrons }}+U_{\mathrm{a}}+\frac{\Phi_{\mathrm{W}}}{e}\right)$

where $e$ is the electron charge; $k_{\mathrm{b}}$ the Boltzmann constant; $U_{\mathrm{c}}$ and $U_{\mathrm{a}}$ the cathode and anode voltage drops, respectively; $\Phi_{\mathrm{i}}$ the argon ionization energy $(13.6 \mathrm{eV})$ and $T_{\text {elec- }}$ trons $=T_{\text {plasma }}$ (LTE assumption).

The cathode and anode voltage drops were supposed to be uniform and equal to 10 and $4 \mathrm{~V}$, respectively. The value of the cathode voltage drop was taken from Ref 2325,28 and that of the anode from Ref 24, 29. Borel (Ref 30) carried out a parametric study to evaluate the sensitivity of predictions to the cathode voltage drop in a transferred arc model. He showed that the heat transfer to the cathode was not affected by the voltage fall when it varied between 0 and $10 \mathrm{~V}$ : The surface temperature of the tungsten cathode was the same.

The value and sign of the anode voltage drop are more questionable than those of the cathode but difficult to measure or calculate for an industrial plasma torch. The choice of a positive anode voltage drop was based on the experimental study of Yang et al. (Ref 31) that showed a positive anode voltage drop was relevant when no intense plasma flow was directed toward the anode surface at the arc attachment. In the study, it was numerically observed that the constricted anode arc attachment brought about an anodic jet directed away from the anode surface and prevented the plasma flow toward the anode.

However, uniform electrode voltage drops are also questionable and electrode sheath models should be implemented to get rid of this assumption. Cathode sheath models are well documented in the literature, e.g., Ref $22,23,25,26$, and are considered in the development of this model. None model has been developed yet for a moving anode arc attachment as observed in plasma spray torch. It could be, however, easier to implement for a cascaded-anode torch as the movement of the arc root is limited to the last ring of the anode and looks like a periodic oscillation according to the arc voltage evolution.

At the anode, the reattachment of the arc was modeled on the basis of the idea proposed by Nemchinsky in a twotemperature model for an argon plasma (Ref 32, 33): In the cold boundary layer next to the anode wall, the electron temperature does not decrease as much as the heavy particle temperature and some residual electrical conductivity subsist in this layer. Under the conditions of this LTE model, an artificial electrical conductivity corresponding to a gas temperature of $6000 \mathrm{~K}$ was imposed behind the anode arc attachment to ensure the flow of electrical current from the plasma to the anode. This electrical conductivity was around $100 \mathrm{~S} \mathrm{~m}^{-1}$ as that predicted by Nemchinsky. It made it possible to simulate a reattachment process characterized by a sinusoidal evolution of the arc voltage as observed for the actual voltage evolution of the Sinplex torch. Without such an artificial electrical conductivity, the electric current could not go through the cold wall boundary layer in the LTE model, and the anode arc attachment was blown downstream up to the outside surface of the anode.

\section{Computational Procedure}

The set of magneto-hydrodynamic equations shown in Table 1 with the boundary conditions listed in Table 2 were solved, in the whole computational domain considered as a fluid domain, with the computational fluid dynamics software Code_Saturne 5.0. (Ref 34) that is a free open-source software developed and released by Electricité de France (EDF) to solve CFD applications. A penalty method adapted from Patankar (Ref 19) was used to ensure a fluid velocity equal to zero in the solid phase (electrodes). This method uses a large source term in the momentum equation $\left(-\Gamma_{\text {impl }}=-10^{30}\right)$ to suppress the 
flow in electrodes. This approach made it possible to have the solid and gas phases in the same computational domain and solve the same set of equations in both phases.

The mesh was made up of $1 \mathrm{M}$ cells: $800 \mathrm{k}$ in the gas phase, $150 \mathrm{k}$ in the cathode and $50 \mathrm{k}$ in the anode. This grid was chosen as the best compromise between rate of convergence, solution accuracy and CPU time required. The cells were hexahedral. The largest cell size was $600 \mu \mathrm{m}$, while the thickness of the first layer of cells was $25 \mu \mathrm{m}$ at the plasma-cathode interface and $50 \mu \mathrm{m}$ at the plasma-anode interface. The groups of cells corresponding to the electrodes were separated from the rest of the domain by virtual thin walls. Custom boundary conditions were imposed on these walls to ensure thermal balance between the gas (argon) and solid (tungsten) phases which have different temperature dependence of enthalpy (Ref 35, 36).

The simulation was performed with 8-12 cores Intel Xeon ${ }^{\circledR}$ E5-2670 v3 Haswell and used 2-3 GB of RAM.

\section{Results and Discussion}

The first step of this study consists in selecting the appropriate boundary condition imposed on the magnetic vector potential at the computational domain limits. The calculations were done for an arc current of $500 \mathrm{~A}$ and gas flow rate of 60 NLPM. Then, the predicted arc voltage and heat loss to the electrodes were compared with experimental values measured by the torch manufacturer for a range of operating conditions selected in the operation window of the plasma torch.

Finally, two different electric boundary conditions for the cathode were compared to determine whether a model that considered the electrodes in the computational domain and a model that considered only the gas phase could bring similar results:

a. recomputed electric potential imposed on the rear face of the cathode when the latter was included in the computational domain,

b. arc current density imposed on the tip of the cathode when only the gas phase was considered.

\section{Effect of the Magnetic Vector Potential Boundary Condition on the Predicted Magnetic Fields}

As explained in Introduction, recent works examined the effect of the boundary conditions for the magnetic vector potential in the model of DC free-burning and constricted transferred arcs (Ref 14, 37). They concluded that null flux of magnetic vector potential, at the boundaries inside the plasma torch and a null value at the outlet boundary (PVNF condition), can yield wrong predictions of the magnetic field when the null flux condition is applied on boundaries close to the arc core. Now, commercial cascaded-anode plasma spray torches have a channel diameter ranging between 6 and $11 \mathrm{~mm}$; the arc fills a large part of the cavity between the cathode tip and nozzle exit and is close to electrode insert and anode walls.

Figure 3 and 4 shows the magnetic field calculated in the fluid with the B\&S and PVNF boundary conditions (Table 2), respectively, for the Sinplex torch with a 9-mm nozzle diameter. Striking differences are observed between the two figures. When the B\&S boundary conditions were used, the predicted magnetic field in the plasma column had a profile similar to that predicted for a cylindrical conductor with uniform current density: The radial variation had (1) a zero value at the center of the discharge, (2) a radial increase in the arc column with a maximum on the edges of the column and (3) a decrease from the periphery of the arc column to the anode wall surface. Far from the arc, the magnetic field reached zero. The maximum value, about $0.05 \mathrm{~T}$ was encountered in the vicinity of the tip of the cathode due to the Maecker effect (Ref 38, 39) and, also, upstream of the anodic arc attachment, where the anodic jet developed.

Figure 5 shows that the predicted magnetic field in a cross-sectional area located at the cathode tip was in good agreement with that calculated from the Ampere's law and the predicted current density:

$B_{\text {theor }}(r)=\frac{\mu_{0}}{2 \pi r} \iint_{S} \vec{J}_{\text {predicted }} \cdot \overrightarrow{\mathrm{d} s}$

where $\vec{J}_{\text {predicted }}$ is the electric current density predicted by the model and $\overrightarrow{\mathrm{d} s}$ is the vector area of an infinitesimal element of surface $S$, enclosed by a circle of radius $r$ and perpendicular to the torch axis.

When a null flux was imposed on all the boundaries inside the torch and null value on the outlet as boundary condition (PVNF condition) for the vector potential (Fig. 4), the projected values of the magnetic field and its distribution were wrong, particularly at the cathode tip, nozzle outlet and anode wall. The same observation was

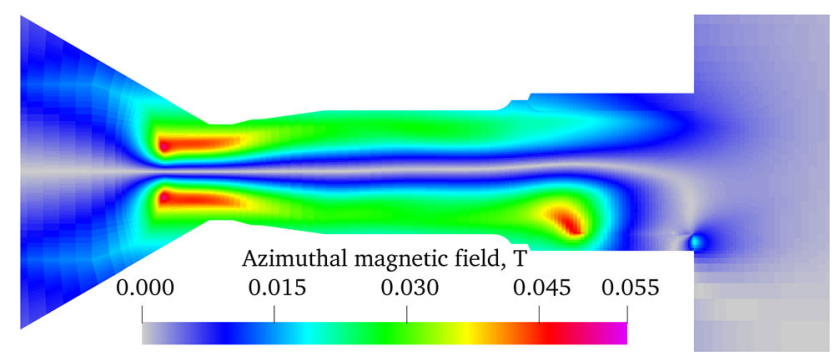

Fig. 3 Azimuthal component of the magnetic field with the B\&S boundary conditions for the magnetic vector potential $(500 \mathrm{~A}, 60$ NLPM, predicted voltage $74 \mathrm{~V}$ ) 


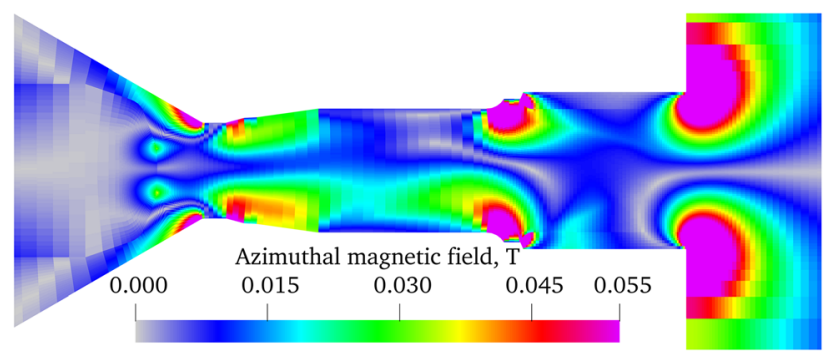

Fig. 4 Azimuthal component of the magnetic field with the PVNF boundary condition for the magnetic vector potential $(500 \mathrm{~A}, 60$ NLPM, predicted voltage $66 \mathrm{~V}$ )

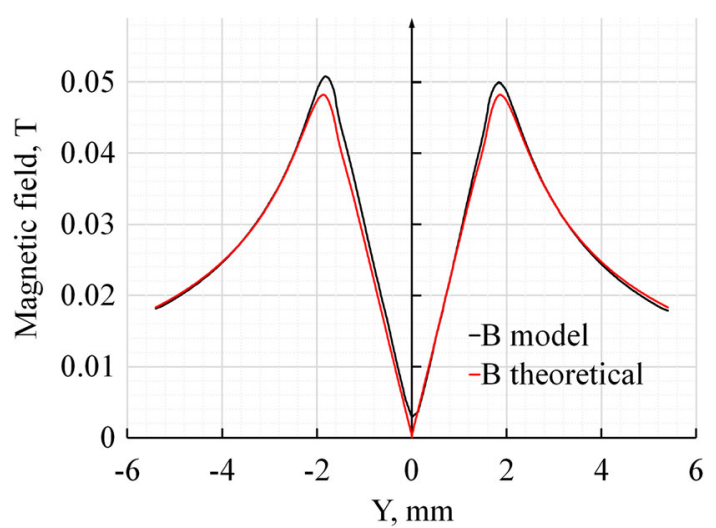

Fig. 5 Comparison of the radial profile of the magnetic field calculated from the Ampere's law, in a plane perpendicular to the torch axis at cathode tip, with the predicted profile when the B\&S boundary condition is used for the magnetic vector potential $(500 \mathrm{~A}$, 60 NLPM, predicted voltage $74 \mathrm{~V}$ )

made in Ref 14 for transferred arcs and free-burning arcs. The corner effect in the predicted magnetic field shown in Fig. 4 brought large fluctuations of the arc and a fast motion of the anode arc attachment.

A question could arise about the effect of the numerical method on such results. Freton (Ref 14) and this study used a finite volume approach to solve the Navier-Stokes equations. In a recent study, Baeva (Ref 40) stated that with the finite elements method (FEM) "the results obtained in the vector potential formulation for a plasma transferred arc with gauge fixing for null flux and null value boundary conditions were both in perfect agreement with the analytical solution." Therefore, we were wondering if the use of the FEM approach with the PVNF (null flux) boundary condition for the magnetic potential vector could result in better results for the magnetic vector potential field in the conditions of this study. Answering this question would require a solver different from the one we are using. However, we have tested the arc geometry (i.e., straight transferred arc) used by Baeva, with the finite volume approach: The magnetic fields were rather similar with the PVNF and Biot\&Savart boundary conditions. Most likely,

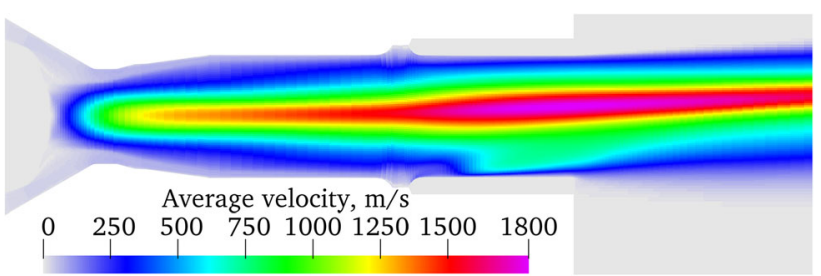

Fig. 6 Predicted time-averaged velocity field when the B\&S boundary condition is used for the magnetic vector potential $(500 \mathrm{~A}, 60$ NLPM)

the differences observed in the condition of this study in the magnetic potential vector field with the PVNF and Biot\&Savart boundary conditions were linked to the geometry of the torch that forces the arc to be close to the walls. This result confirms the conclusions of Freton (Ref 14).

\section{Effect of the Magnetic Vector Potential Boundary Condition on the Predicted Gas Velocity and Temperature Fields}

Figure 6 and 7 shows the time-average plasma velocity field calculated with the B\&S and PVNF boundary conditions (Table 2), respectively. The plasma flow reached a maximum velocity of about $1800 \mathrm{~m} \mathrm{~s}^{-1}$ on the jet axis at $38 \mathrm{~mm}$ downstream of the cathode tip with the B\&S condition, while it reaches $1000 \mathrm{~m} \mathrm{~s}^{-1}$ at $8 \mathrm{~mm}$ with the PVNF condition. The flow expands much further with the $\mathrm{B} \& \mathrm{~S}$ condition. The same observation can be done for the time-average plasma temperature fields shown in Fig. 8 and 9 calculated with the B\&S and PVNF boundary conditions, respectively.

Actually, in a DC spray plasma torch, the plasma jet originates close to the cathode surface where the selfmagnetic field associated with the arc produces a compressive force inward on the $\operatorname{arc}(\vec{J} \wedge \vec{B})$. This force is balanced by an increase in the gas radial pressure gradient and, therefore, the pressure increases inside the arc (Ref 38 ) with the highest values close to the cathode.

The pressure gradient in the arc accelerates the plasma flow and induces the cathode jet. The plasma velocity is thus affected by the magnetic pressure and correct projections of the plasma flow velocity field require realistic predictions of the magnetic field, as explained by Freton et al. (Ref 14).

\section{Comparison of Predictions with Experimental Data}

When using the $\mathrm{B} \& \mathrm{~S}$ boundary conditions for the magnetic potential vector, the predictions of the arc voltage and heat loss to electrodes were in good agreement with the data measured by the manufacturer for low plasma gas flow 


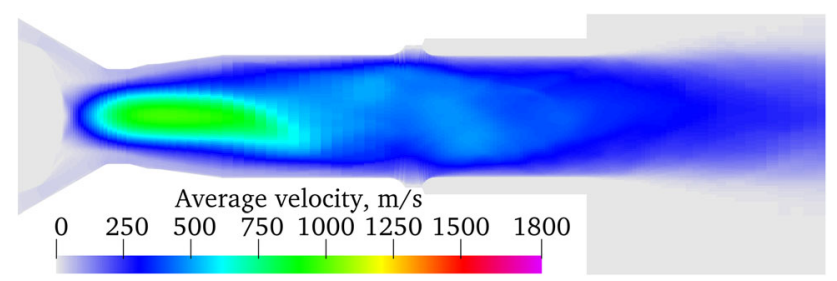

Fig. 7 Predicted time-averaged plasma velocity field when the PVNF boundary condition is used for the magnetic vector potential $(500 \mathrm{~A}$, 60 NLPM)

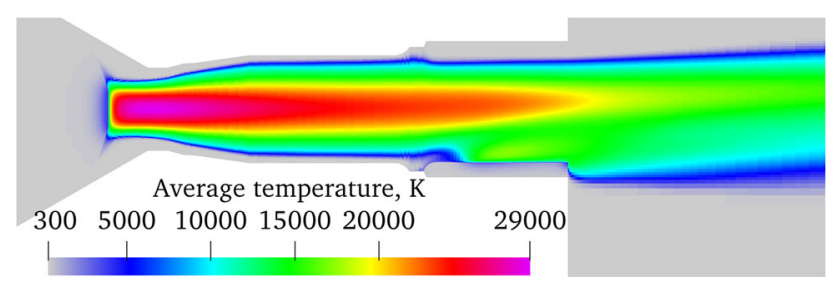

Fig. 8 Predicted time-averaged plasma temperature field when the B\&S boundary condition is used for the magnetic vector potential (500 A, 60 NLPM)

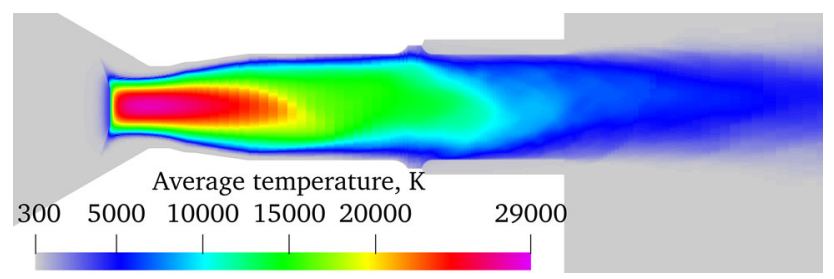

Fig. 9 Predicted time-averaged plasma temperature field when the PVNF boundary condition is used for the magnetic vector potential (500 A, 60 NLPM)

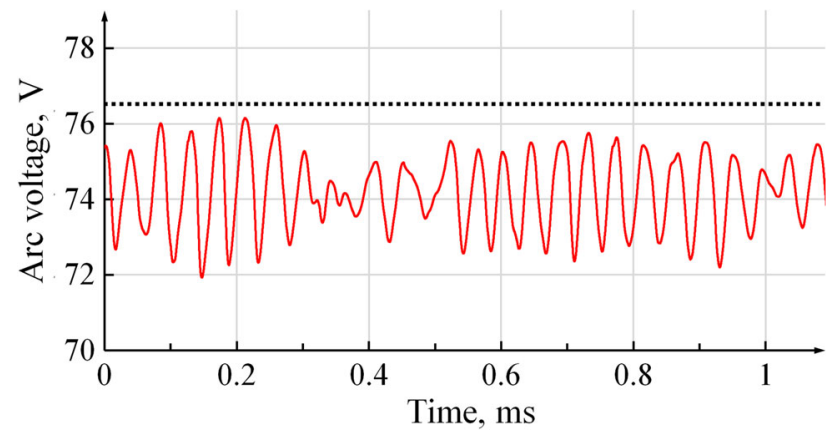

Fig. 10 Predicted time evolution of arc voltage for $500 \mathrm{~A}$ and $60 \mathrm{Ar}$ NLPM

rates and high arc current intensities. For instance, for an arc current of $500 \mathrm{~A}$ and 60 SLPM of argon, the predicted arc voltage and heat loss to electrodes were $74 \pm 2 \mathrm{~V}$ and $14.9 \pm 1.3 \mathrm{~kJ}$, respectively, while the actual ones were $76 \pm 4 \mathrm{~V}$ and $14.2 \pm 0.8 \mathrm{~kJ}$, respectively. For these operating conditions, the time-average variation of the predicted arc voltage was about $5 \mathrm{~V}$ as shown in Fig. 10.

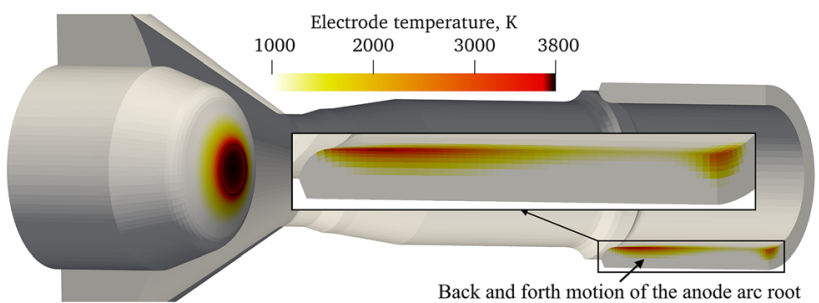

Fig. 11 Predicted electrode temperature for $500 \mathrm{~A}$ and 60 Ar NLPM. The increase in anode temperature caused by the arc root motion is visible in the lower part of the anode

This small variation is explained (1) by the inter-electrode insert that forces the arc to attach to the last ring and restricts its motion to the ring length and (2) the back and forth movement of the arc on a line on the anode wall as displayed in Fig. 11 that shows the time-average temperature of electrodes. However, if the predicted voltage is in good agreement with the actual voltage, it should be noted that in this LTE model, it depends on the artificial electrical conductivity imposed behind the anode arc attachment to force the arc to go through the cold wall boundary layer. In addition, the predicted value did not take into account the anode and cathode voltage drop, which are partially compensated by the overestimation due the LTE assumption (Ref 35).

Figure 12 shows the variation of the predicted and actual arc voltage with the arc current for a gas flow rate of 60 and 120 SLPM. Contrarily to the common plasma torches, under the range of operating conditions of this study, the cascaded arc showed an ascending voltage-current characteristics whatever the argon gas flow rate was. Indeed, in non-cascaded arc plasma torch, the arc voltage decreases when the current increases as the arc conductance increases because of an increase of the temperature in the plasma core and so of the electrical conductivity, or a decrease in the arc diameter or both (Ref 41, 42). In the SinplexPro ${ }^{\mathrm{TM}}$ torch, the insert prevents the shortening of the arc with increasing current (Ref 42). As a result, the total power $(P=U \cdot I)$ dissipated by the torch increased by the increase of both the arc current and voltage when arc current is increased.

Figure 12 shows also that if the predicted voltage and actual voltage were in good agreement for low plasma gas flow rate and high current, they began to disagree when the gas flow rate was increased and current decreased. Actually, the LTE assumption used in this arc model is not valid any longer in such conditions as a high gas flow rate or low electric current results in a thicker or faster cold boundary layer that favors the arc instability. Under such operating conditions, the validity of the LTE approach is questionable: The arc is too resistive and unstable; the arc voltage fluctuations are too high and arc voltage is overestimated. 


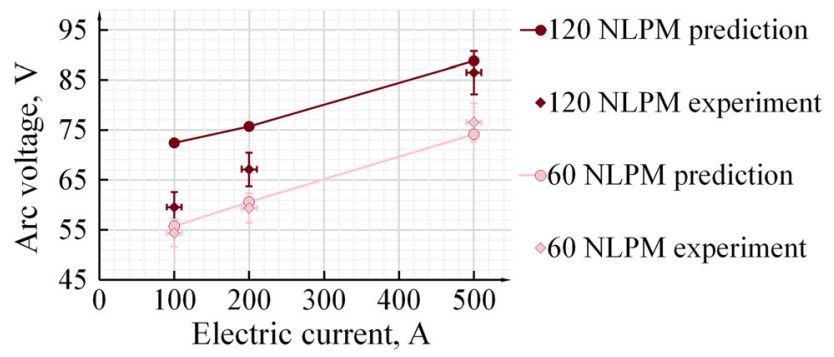

Fig. 12 Variation of time-averaged arc voltage vs. arc current

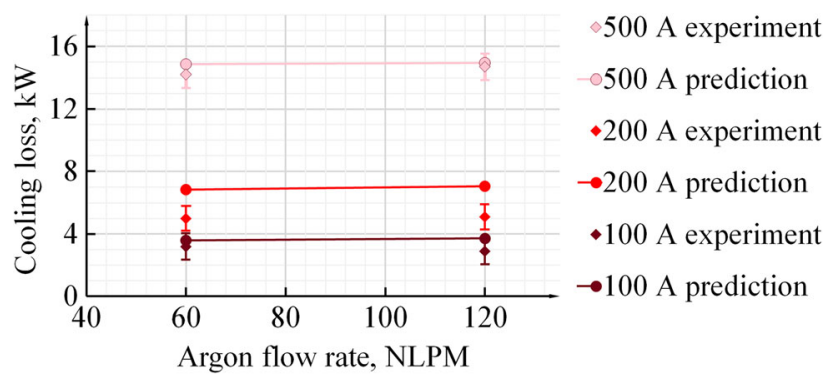

Fig. 13 Variation of cooling loss to both electrodes vs. argon gas flow rate for arc current of 100, 200 and $500 \mathrm{~A}$

It should be noted that the actual arc voltage increases almost linearly with the gas flow rate for the range of gas flow rates (60-120 NLPM) considered in this study.

Figure 13 shows the predicted and experimental heat loss to electrodes as a function of the argon flow rate. Unlike arc voltage, the heat loss data are in a good agreement for plasma gas flow rates ranging between 60 and 120 NLPM. The calculated trends are correct that is a very low increase with the gas flow rate and a much higher increase with the current intensity because of the heat flux to anode brought by the electron current density that increases with arc current. Therefore, the plasma torch thermal efficiency (defined as $(U \cdot I-Q) / U \cdot I$ where $U$, $I$ and $Q$ are the arc voltage, arc current and total loss to electrodes, respectively) essentially depends on the current intensity; it can reach $65 \%$ for an argon plasma at $500 \mathrm{~A}$ and a gas flow rate of 60 SLPM, which is higher than the thermal efficiency of conventional plasma torches (40$60 \%$ ) under the same operating conditions (Ref 43).

The specific enthalpy $(h)$ of the plasma jet is defined as the ratio of the total enthalpy of the gas flow $(\eta \cdot U \cdot I)$ to the gas mass flow rate $(\dot{m})$. It represents the energy available per unit mass of the flow and is more informative than the torch power to compare set of operating parameters for a given plasma gas. The plasma specific enthalpy at nozzle exit drawn from the experimental values of the arc current $(I)$, voltage $(U)$, torch thermal efficiency $(\eta)$ ranged between $1.08 \mathrm{MJ} \mathrm{kg}^{-1}$ at $100 \mathrm{~A}$ and $120 \mathrm{NLPM}$ and $13.46 \mathrm{MJ} \mathrm{kg}^{-1}$ at $500 \mathrm{~A}$ and $60 \mathrm{NLPM}$. For an arc current

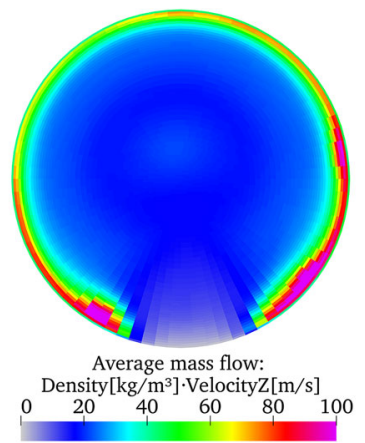

(a)

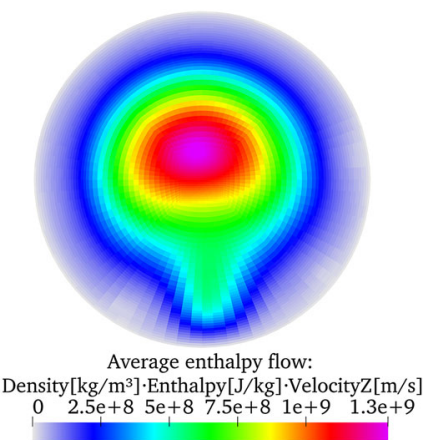

(b)
Fig. 14 (a) Gas mass flow $\left(\mathrm{kg} \mathrm{m}^{-2} \mathrm{~s}^{-1}\right)$ and (b) enthalpy flow $\left(\mathrm{J} \mathrm{m}^{-2} \mathrm{~s}^{-1}\right)$ rate of plasma jet in the nozzle exit plane $(500 \mathrm{~A}, 60$ NLPM) when the B\&S boundary condition is used for the magnetic vector potential

of $500 \mathrm{~A}$ and gas flow rate of 60 NLPM, the predicted mass flow rate

$$
\left(\dot{m}=\int_{S} \rho \cdot \vec{u} \cdot \vec{n} \cdot \mathrm{d} s=1.77 \times 10^{-3} \mathrm{~kg} / \mathrm{s}\right)
$$

and enthalpy flow rate

$$
\left(\dot{h}=\int_{\mathrm{S}} \rho \cdot h \cdot \vec{u} \cdot \vec{n} \cdot \mathrm{d} s=23.8 \times 10^{3} \mathrm{~J} / \mathrm{s}\right)
$$

in the anode exit plane (Fig. $14 \mathrm{a}$ and b) resulted in a plasma jet specific enthalpy $h$ of $13.43 \mathrm{MJ} \mathrm{kg}^{-1}$, while the experimental one was $13.46 \mathrm{MJ} \mathrm{kg}^{-1}$. It should be noted that under the same operating conditions, the plasma specific enthalpy for a conventional plasma torch is less than $8 \mathrm{MJ} \mathrm{kg}^{-1}(\operatorname{Ref} 43)$.

\section{Is It Possible to Get the Same Results with a Model that Considers Only the Gas Phase?}

Answering this question requires to compare the predictions of this model that solves the electromagnetic and heat equations in the electrodes and gas phase, with a model that considers only the gas phase. Contrarily to the former model that predicts the current density profile at the cathode tip, the latter model requires to select and impose this profile at the cathode tip. Generally, it is expressed as a parabolic or an exponential law (e.g., Ref 4-6), but does such a profile that is well adapted to sharpened cathodes, work for the Sinplex cathode shape (Fig. 1)? Therefore, the first step was to predict the current density profile at the Sinplex cathode with the model used in this study and the second step to implement this profile in a model limited to the gas phase (Ref 35).

Figure 15 shows the electric current lines in the electrodes and gas phase colored by the current density for an arc current of $500 \mathrm{~A}$ and gas flow rate of 60 NLPM. As expected, the current lines were perpendicular to the surface of the electrodes. The maximum current density, close 


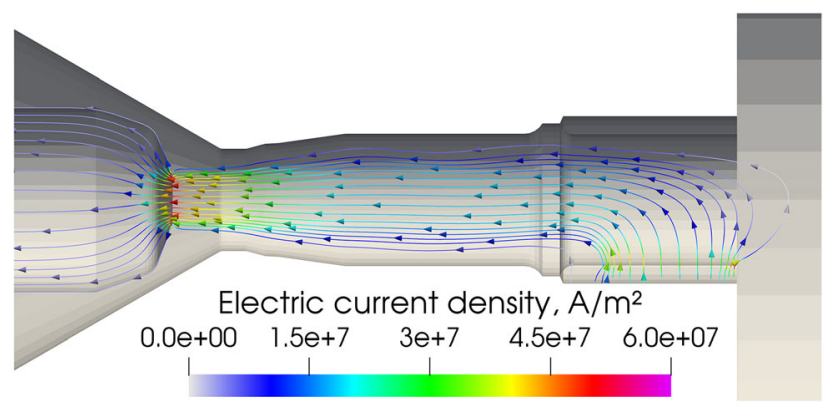

Fig. 15 Electric current density field in cathode tip and gas phase (500 A, 60 NLPM)

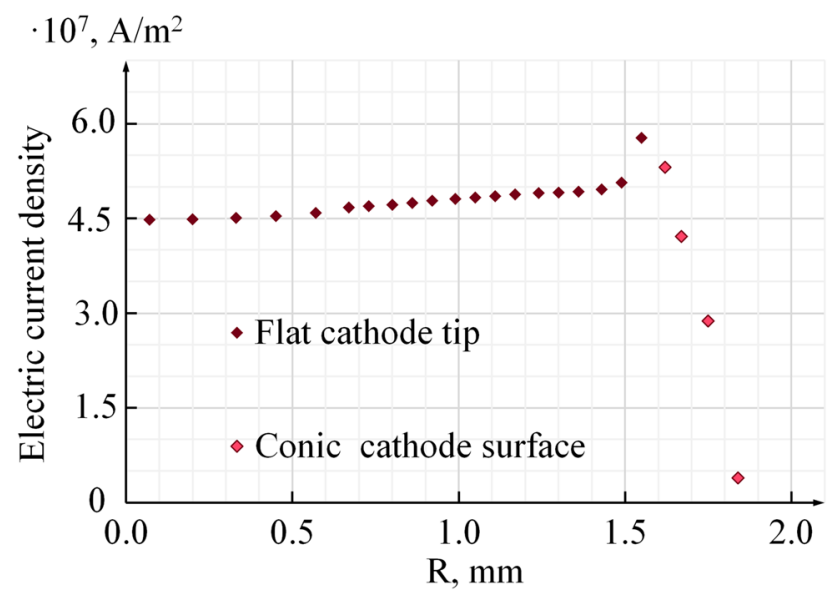

Fig. 16 Current density profile at cathode tip (500 A, 60 NLPM)

to $5 \times 10^{7} \mathrm{~A} \mathrm{~m}^{-2}$, was encountered at the cathode end; it then decreases in the cathode bulk to a constant value where the section of the cathode is constant. The predicted current density profile at the cathode tip is shown in Fig. 16: The maximum of the current density profile was on the edge of the cathode (truncated part) and not on its axis. This could be explained by a peak effect related to the specific shape of the cathode. The projected maximum temperature (Fig. 17) reached by the tungsten cathode tip was $3700 \mathrm{~K}$, and the geometry (depth and width) of the molten zone was found to depend more on the arc current than plasma gas flow.

This profile is different from those generally used in plasma torch models as boundary conditions, such as $j=$ $j_{0} \exp \left(-\left(\frac{r}{R_{\text {arc }}}\right)^{n}\right)$ where $j_{0}, R_{\text {arc }}$ and $\mathrm{n}$ are parameters that make it possible to adapt the profile shape. Therefore, the current density profile previously calculated with the inclusion of the electrodes in the calculation domain (Fig. 16) was imposed at the cathode tip in a model that is limited to the gas phase. Figure 18 shows the distribution of the magnetic field predicted by this model. This distribution is similar to the distribution calculated with the

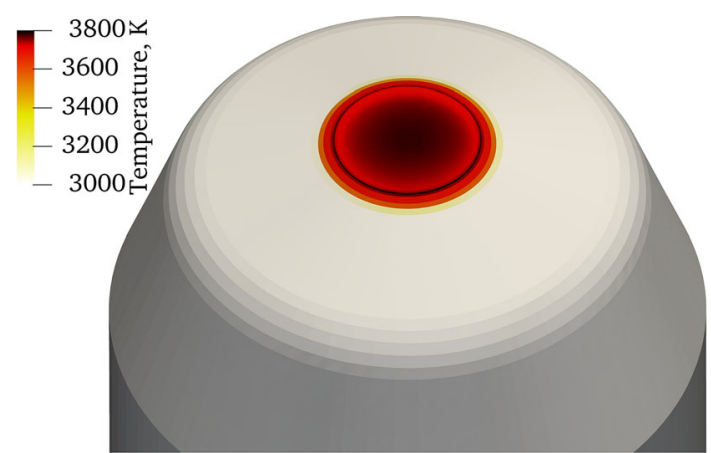

Fig. 17 Projected cathode surface temperature (500 A, 60 NLPM of argon)

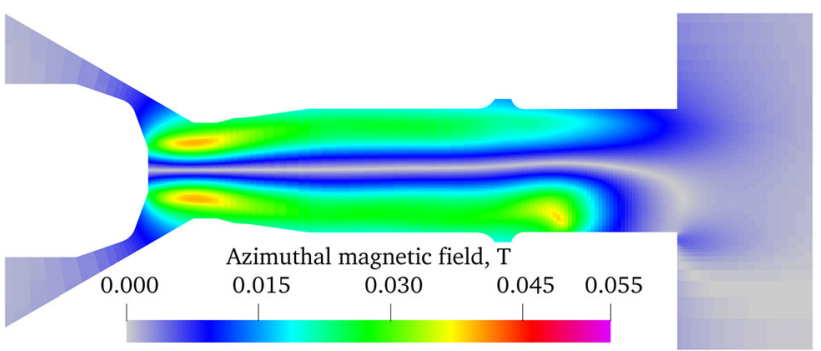

Fig. 18 Azimuthal component of the magnetic field in the case without the electrodes (500 A, 60 NLPM, voltage $73.1 \mathrm{~V}$ ). The BS law was used for the boundary conditions of the magnetic vector potential

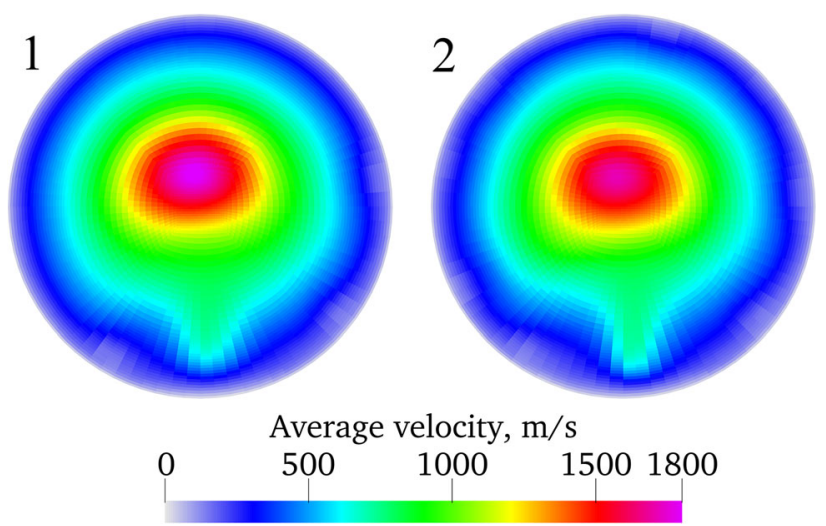

Fig. 19 Time-averaged velocity distribution at the torch outlet: $1-$ with the electrodes in the calculation domain and 2-without the electrodes

electrodes in the domain (Fig. 3) except that the magnetic field at the cathode tip is twice lower than the magnetic field predicted with electrodes. In the latter case, the contribution related to the passage of the current in the solid cathode was taken into account and the self-induced magnetic field at cathode tip was higher.

It should be noted that both models used the Biot and Savart formulation for the magnetic vector potential. With such a boundary condition, the effect of the inclusion or not 
of the electrodes in the calculation domain on the predicted plasma jet velocity and temperature fields at nozzle was hardly noticeable as observed in Fig. 19 and 20 that represent the plasma time-average temperature and velocity distributions, respectively, in the plane of the nozzle exit.
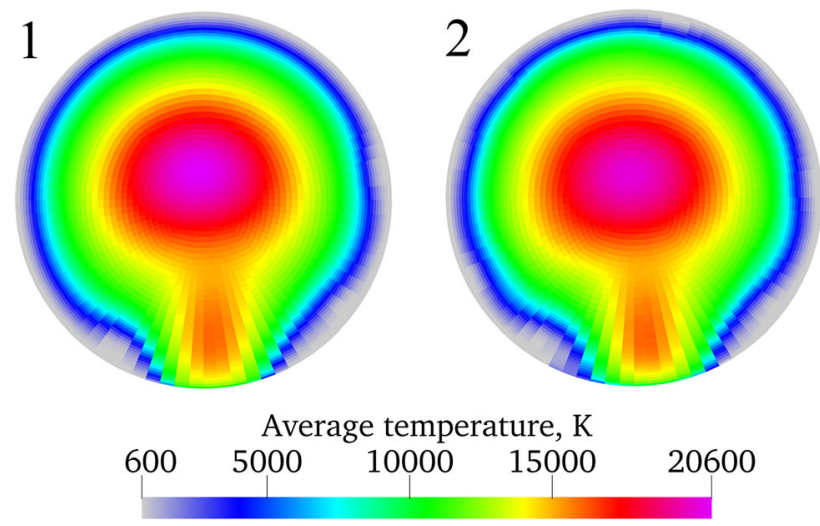

Fig. 20 Time-averaged temperature distribution at the torch outlet: 1 -with the electrodes in the calculation domain and 2-without the electrodes

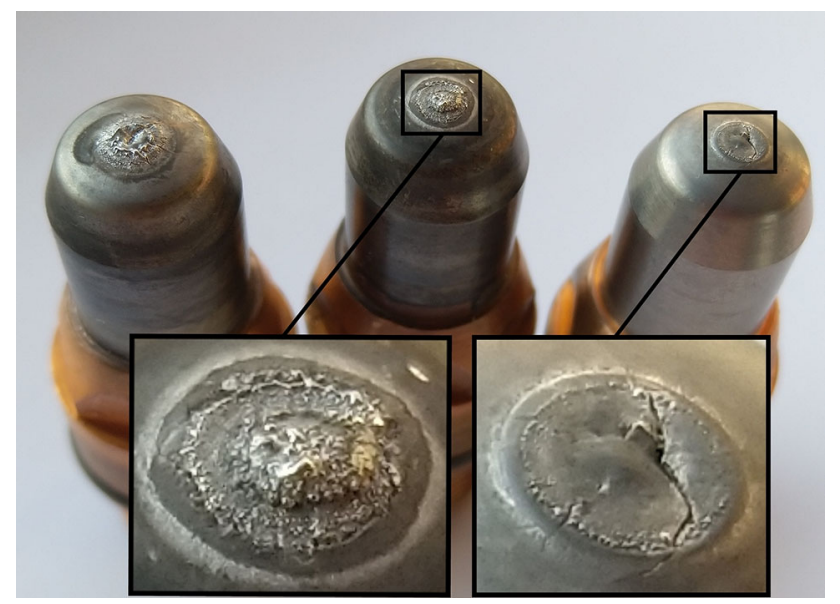

Fig. 21 Used doped tungsten cathodes of SinplexPro ${ }^{\mathrm{TM}}$ Plasma Spray Gun
This study showed that almost similar results were obtained when the electrodes were included in the computational domain and when only the gas phase was considered and a current density profile imposed on the tip of the cathode. However, it also showed that the latter profile has to be the correct one. If the latter can be easily modeled by a parabolic or exponential function for sharpened cathodes, it is much trickier to determine for the cathode shape of the SinplexPro ${ }^{\mathrm{TM}}$ plasma torch. Actually, the only way to have the right profile is either to "measure" it or draw it from numerical simulations that include the electrodes in the computational domain.

Finally, another question arises about the current density profile (Fig. 16) at the cathode tip predicted by the model that includes the electrodes in the computational domain: Is it realistic?

The postmortem observation by optical microscopy of actual cathodes (Fig. 21) revealed a "ring" on the edge of the truncated end and small spheres of resolidified tungsten droplets. At first sight, these observations seemed to confirm the predicted current density profile with the maximum on the edge of the cathode (Fig. 16). However, at least two assumptions of the LTE model that can affect this profile are questionable: the cathode material and constant cathode voltage drop. In the actual Sinplex plasma torch, both the cathode and anode liner are made of tungsten doped with lanthanum oxide $(1.5 \%)$. The main roles of the dopant are to lower the work function of cathode $(2-2.8 \mathrm{eV}$ for lanthanum instead of about $4.5 \mathrm{eV}$ for tungsten) and improve the arcing behavior and machinability of tungsten (Ref 44, 45). For the same arc current, the doped cathode is operated at a lower temperature. Figure 22 shows the temperature of the cathode tip predicted by this model for a pure tungsten and a lanthanum-doped cathode at $500 \mathrm{~A}$ and 60 NLPM: If the tungsten cathode reached the melting temperature, the doped cathode worked at a temperature about $900 \mathrm{~K}$ lower and did not melt. The dopant lowers the cathode surface temperature; its behavior during arcing also affects the stability of the arc. Sadek et al. (Ref 45) have experimentally observed that the rare-earth oxide
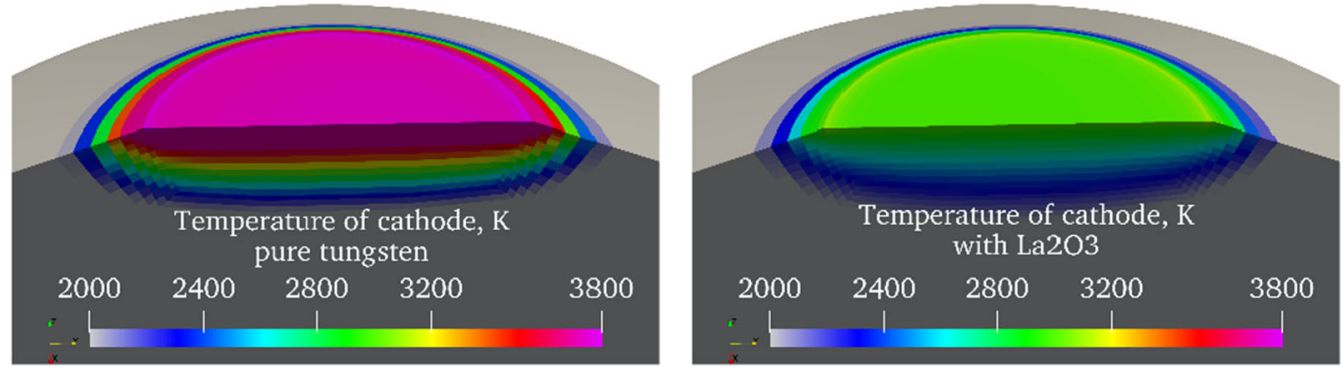

Fig. 22 Predicted temperature of cathode tip for 500 A and 60 Ar NLPM. Left-hand figure: pure tungsten; right-hand figure: tungsten doped with $\mathrm{La}_{2} \mathrm{O}_{3}$ 
reacted with tungsten and formed tungstate and oxytungstate that migrated from the lower- to the highertemperature zones. The distribution of the rare-earth oxide changed and concentrated at some places determined by the cathode temperature distribution, modifying also the appearance of the cathode. Therefore, the definitive validation of the current density profile would require (1) to implement a model of dopant reaction with tungsten, diffusion in the cathode and evaporation and Ref 45, 46, (2) to investigate actual cathode microstructure and composition after operation in given conditions and (3) to implement a cathode sheath model to calculate the voltage drop variation. This is beyond the scope of this study that aimed to investigate the effect of the electromagnetic boundary conditions of the model.

\section{Conclusion}

A reliable and fully predictive model of the operation of a DC plasma spray torch is a very useful tool for testing different geometries and operating conditions (Ref 47, 48). Powerful hardware platforms and cloud computing make it possible to run complex plasma torch models, but each feature of a model must be clearly stated.

This study examined the effect of the assumed boundary conditions for the magnetic potential vector and electric current density on the plasma fields in the torch arc chamber. A commercial plasma torch with a single cathode and a cascaded anode was modeled.

First, the plasma fields predicted with the most frequently used boundary condition for the magnetic vector potential (null flux imposed at the physical limits of the domains and zero magnetic vector potential when these limits are far from the arc) were compared with those obtained when the exact values of the vector potential at the domain boundaries were calculated by using the Biot and Savart law. The model predictions showed that when the arc is strongly constricted by a nozzle as in the case a plasma spray torch, the Biot and Savart formalism results in more realistic magnetic and velocity fields.

The second part of the study compared the predictions obtained when the electrodes were included in the computational domain versus the case when the domain is limited to the gas phase and a current density profile is imposed at the cathode tip. The results were similar if the correct current density profile is used. However, to model a plasma torch with a non-common cathode geometry, e.g., the Sinplex torch, it is necessary to calculate the current and heat flow in the electrodes in order to obtain the right current density profile at the cathode tip. Also, including the electrodes in the computational domain and solving the heat and electromagnetic equation in the solid and gas phases allows for determining the heat flux to the electrodes and reducing their erosion.

Finally, several points required to develop a predictive model of a plasma spray torch were not tackled in this study (Ref 1,2). They involve the calculation of the voltage drop at cathode and anode by including electrode sheath model on both electrodes. Many recent models (e.g., Ref $11,49)$ include the cathode sheath model but generally consider transferred arcs; the anode sheath for DC nontransferred arcs requires the development of a reliable model of the arc movement on the anode wall. It is believed that the anode sheath model will be easier to use for cascaded arcs (e.g., SinplexPro ${ }^{\mathrm{TM}}$ plasma torch) where the arc motion can be described by a takeover mode. Another important point is the correct description of the thermal disequilibrium at the fringes of the jet and close to the walls (electrodes, etc.). This can be done by implementing a two-temperature (2-T) model for the electrons and heavy particles. Again, many technical papers deal with 2-T model for plasma torches (e.g., Ref 50-53). This model is now being implemented in the open-source CFD software Code_Saturne 5.0.

Acknowledgments The authors would like to thank Alexander Barth and Hartmut Koschnitzke, Oerlikon Metco Wohlen, Switzerland, and Jose Colmenares, Oerlikon Metco, Westbury, USA, for valuable discussion, Yvan Fournier, EDF R\&D, Chatou, France, for help with Code_Saturne and Frederic Bernaudeau and Nicolas Calvé, IRCER, for their technical help with the computers.

Open Access This article is licensed under a Creative Commons Attribution 4.0 International License, which permits use, sharing, adaptation, distribution and reproduction in any medium or format, as long as you give appropriate credit to the original author(s) and the source, provide a link to the Creative Commons licence, and indicate if changes were made. The images or other third party material in this article are included in the article's Creative Commons licence, unless indicated otherwise in a credit line to the material. If material is not included in the article's Creative Commons licence and your intended use is not permitted by statutory regulation or exceeds the permitted use, you will need to obtain permission directly from the copyright holder. To view a copy of this licence, visit http://creativecommons. org/licenses/by/4.0/.

\section{References}

1. C. Chazelas, J.P. Trelles, and A. Vardelle, The Main Issues to Address in Modeling Plasma Spray Torch Operation, J. Therm. Spray Technol., 2017, 26(1-2), p 3-11

2. C. Chazelas, J.P. Trelles, I. Choquet, and A. Vardelle, Main Issues for a Fully Predictive Plasma Torch Model and Numerical Considerations, Plasma Chem. Plasma Process., 2017, 37(3), p $627-651$

3. J.P. Trelles, Advances and Challenges in Computational Fluid Dynamics of Atmospheric Pressure Plasmas, Plasma Sources Sci. Technol., 2018, 27(9), p 093001

4. B. Selvan, K. Ramachandran, K.P. Sreekumar, T.K. Thiyagarajan, and P.V. Ananthapadmanabhan, Three-Dimensional 
Numerical Modeling of an Ar-N2 Plasma Arc Inside a NonTransferred Torch, Plasma Sci. Technol., 2009, 11(6), p 679-687

5. J.P. Trelles and S.M. Modirkhazeni, Variational Multiscale Method for Nonequilibrium Plasma Flows, Comput. Methods Appl. Mech. Eng., 2014, 282, p 87-131

6. E. Dalir, C. Moreau, and A. Dolatabadi, Three-Dimensional Modeling of Suspension Plasma Spraying with Arc Voltage Fluctuations, J Therm. Spray Technol., 2018, 27, p 1465-1490

7. V. Rat and J.F. Coudert, Pressure and Arc Voltage Coupling in DC Plasma Torches: Identification and Extraction of Oscillation Modes, J. Phys. D Appl. Phys., 2010, 108(4), p 043304

8. J.F. Coudert and V. Rat, Influence of Configuration and Operating Conditions on the Electric Arc Instabilities of a Plasma Spray Torch: Role of Acoustic Resonance, J. Phys. D Appl. Phys., 2008, 41, p 205208

9. A.B. Murphy, A Perspective on Arc Welding Research: The Importance of the Arc, Unresolved Questions and Future Directions, Plasma Chem. Plasma Process., 2015, 3(3), p 471-489

10. M. Schnick, U. Fuessel, M. Hertel, M. Haessler, A. Spille-Kohoff et al., Modelling of Gas Metal Arc Welding Taking into Account Metal Vapour, J. Phys. D Appl. Phys., 2010, 43(43), p 434008

11. A.J. Shirvan and I. Choquet, A Review of Cathode-Arc Coupling Modelling in GTAW, Weld. World, 2016, 60(4), p 821-835

12. M. Alaya, C. Chazelas, and A. Vardelle, Parametric Study of Plasma Torch Operation Using a MHD Model Coupling the Arc and Electrodes, J. Therm. Spray Technol., 2016, 25(1-2), p 36-43

13. P. Liang and R. Groll, Numerical Study of Plasma-Electrode Interaction During Arc Discharge in a DC Plasma Torch, IEEE Trans. Plasma Sci., 2018, 46(2), p 363-372

14. P. Freton et al., Magnetic Fields Approaches in DC Thermal Plasma Modelling, J. Phys. D Appl. Phys., 2011, 44, p 345202

15. DSE-0061.5 SinplexPro Universal Plasma Spray Guns, https:// www.oerlikon.com/metco/en/products-services/coating-equip ment/thermal-spray/spray-guns/coating-equipment-plasma/ sinplexpro/

16. M. Shigeta, Turbulence Modelling of Thermal Plasma Flows, $J$. Phys. D Appl. Phys., 2016, 49, p 493001

17. A. Lebouvier, C. Delalondre, F. Fresnet, V. Boch, V. Rohani et al., Three-Dimensional Unsteady MHD Modeling of a LowCurrent High-Voltage Nontransferred DC Plasma Torch Operating with Air, IEEE Trans. Plasma Sci., 2011, 39(9), p 1889-1899

18. A. Gleizes, J. Gonzalez, and P. Freton, Thermal Plasma Modelling, J. Phys. D Appl. Phys., 2005, 38(9), p R153-R183

19. S. Patankar, Numerical Heat Transfer and Fluid Flow, Hemisphere Publishing Corporation, Washington, 1980

20. A. Essoltani, P. Proulx, M.I. Boulos, and A. Gleizes, Volumetric Emission of Argon Plasmas in the Presence of Vapors of Fe, Si, and Al, Plasma Chem. Plasma Proc., 1994, 14(4), p 437-450

21. A.B. Murphy, Transport Coefficients of Hydrogen and ArgonHydrogen Plasmas, Plasma Chem. Plasma Process., 2000, 20(3), p 279-297

22. A. Javidi Shirvan, Modelling of Electric Arc Welding: ArcElectrode Coupling. Lic. Thesis, Chalmers University of Technology, Sweden, 2013

23. F. Cayla, P. Freton, and J. Gonzalez, Arc/Cathode Interaction Model, IEEE Trans. Plasma Sci., 2008, 36, p 1944-1954

24. W. Neumann, Electrode Processes in High Pressure Gas Discharge, Experimental Studies of Plasma Torches, M.F. Zhukov, Ed., Nauka, Novosibirsk, 1977, p 253-292 ((in Russian))

25. M.S. Benilov and A. Marotta, A Model of the Cathode Region of Atmospheric Pressure Arcs, J. Phys. D: Appl. Phys., 1995, 28, p 1869

26. I. Choquet, H. Nilsson, and H. Jasak, Coupling Boundary Condition for High-Intensity Electric Arc Attached on a Non-homogeneous Refractory Cathode, Comput. Phys. Commun., 2018, 222, p 31-45
27. A.L. Reimann, Thermionic Emission, Chapman \& Hall Ltd, London, 1934

28. A. Khrabry, I.D. Kaganovich, V. Nemchinsky, and A. Khodak, Investigation of the Short Argon Arc with Hot Anode. I. Numerical Simulations of Non-equilibrium Effects in the NearElectrode Regions, Phys. Plasmas, 2018, 25, p 013521

29. M. Tanaka and M. Ushio, Observations of the Anode Boundary Layer in Free-Burning Argon Arcs, J. Phys. D: Appl. Phys., 1999, 32, p 906-912

30. D. Borel, Numerical and Experimental Study of Heat Transfer in Arc Plasma: Application to Arc Welding, University of Rouen, Mont-Saint-Aignan, 2013 ((in French))

31. G. Yang and J. Heberlein, Anode Attachment Modes and Their Formation in a High Intensity Argon Arc, Plasma Sources Sci. Technol., 2007, 16, p 529

32. V.A. Nemchinsky, On Conductivity of Cold Gas Layer Separating Arc Column and Nozzle in Non-transferred Plasma Arc, IEEE Trans. Plasma Sci., 2015, 43, p 2715-2721

33. V.A. Nemchinsky, Arc Discharge Anode Reattachment: Simple Model, IEEE Trans. Plasma Sci., 2014, 42(12), p 4026-4030

34. Code Saturne 5.0.0 Theory Guide, EDF R\&D, 2017, p 393-398, (in French), https://www.code-saturne.org/cms/sites/default/ files/docs/5.0/theory.pdf

35. R. Zhukovskii, Towards a Reliable Numerical Model of DC Plasma Spray Torch Operation, $\mathrm{PhD}$ Thesis, University of Limoges, Limoges France, 2020

36. R. Zhukovski, C. Chazelas, A. Vardelle, and V. Rat, Control of the Arc Motion in DC Plasma Spray Torch with a Cascaded Anode, J. Therm. Spray Technol., 2020, 29, p 3-12

37. I. Choquet, A. Javidi Shirvan, and H. Nilsson, On the Choice of Electromagnetic Model for Short High-Intensity Arcs, Applied to Welding, J. Phys. D: Appl. Phys., 2012, 45, p 205203

38. H. Maecker, Plasmastromungen in Lichtbogen infolge eigenmagnetischer compression, Zeitschrift für Physik., 1955, 141(12), p 198-216 ((in German))

39. J. Lowke, A Unified Theory of Arcs and their Electrodes, J. Phys. IV France, 1997, 07(C4), p C4-283-C4-294

40. M. Baeva, Non-equilibrium Modeling of Tungsten-Inert Gas Arcs, Plasma Chem. Plasma Process., 2017, 37, p 341-370

41. S. Vacquier, Arc électrique, Librairie Eyrolles, 2000, (in French)

42. R. Ramasamy and V. Selvarajan, Current-Voltage Characteristics of a Non-transferred Plasma Spray Torch, Eur. Phys. J. D, 2000, 8(1), p 125-129

43. P. Fauchais, J.V.R. Heberlein, and M. Boulos, Thermal Spray Fundamentals: From Powder to Part, Springer, New York, 2014, p 402

44. J. Colmenares-Angulo, R. Molz, D. Hawley et al., Thorium-Free Versus Thoriated Plasma Gun Electrodes: Statistical Evaluation of Coating Properties, J. Therm. Spray Technol., 2016, 25, p 622630

45. A. Sadek, M. Ushio, and F. Matsuda, Effect of Rare Earth Metal Oxide Additions to Tungsten Electrodes, Metall. Trans. A, 1990, 21(12), p 3221-3236

46. V. Nemchinsky, Life Time of a Refractory Cathode Doped with a Work-Function-Lowering Dopant, J. Phys. D: Appl. Phys., 1996, 29, p 2417-2422

47. K. Bobzin, M. Öte, J. Schein, and S. Zimmermann, Numerical Study on Plasma Jet and Particle Behavior in Multi-arc Plasma Spraying, J. Therm. Spray Technol., 2017, 26(5), p 811-830

48. R. Chidambaram Seshadr and S. Sampath, Characteristics of Conventional and Cascaded Arc Plasma Spray-Deposited Ceramic Under Standard and High-Throughput Conditions, J Therm. Spray Technol., 2019, 28(4), p 690-705

49. J. Gonzalez, F. Cayla, P. Freton, P. Teulet et al., Two-Dimensional Self-Consistent Modelling of the Arc/Cathode Interaction, J. Phys. D Appl. Phys., 2009, 42(14), p 145204 
50. S.M. Modirkhazeni and J.P. Trelles, Non-transferred Arc Torch Simulation by a Non-equilibrium Plasma Laminar-to-Turbulent Flow Model, J. Therm. Spray Technol., 2018, 27(8), p 1447-1464

51. J.P. Trelles, J.V.R. Heberlein, and E. Pfender, Non-equilibrium Modelling of Arc Plasma Torches, J. Phys. D Appl. Phys., 2007, 40(19), p 5937-5952

52. P. Freton, J.J. Gonzalez, Z. Ranarijaona, and J. Mougenot, Energy Equation Formulations for Two-Temperature Modelling of 'Thermal' Plasmas, J. Phys. D Appl. Phys., 2012, 45(46), p 465206
53. M. Baeva, D. Uhrlandt, M.S. Benilov, and M.D. Cunha, Comparing Two Non-equilibrium Approaches to Modelling of a FreeBurning Arc, Plasma Sources Sci. Technol., 2013, 22(6), p 065017

Publisher's Note Springer Nature remains neutral with regard to jurisdictional claims in published maps and institutional affiliations. 